\title{
Enhancing Innovation Potential through Local Capacity Building in Education
}

\author{
Jaana Holvikivi \\ Helsinki Metropolia University of Applied Sciences, Finland \\ jaana.holvikivi@metropolia.fi
}

\begin{abstract}
Global technology education is largely dominated by Western universities. Students from developing countries face an enormous challenge when moving from their local education system into the competitive international education market. Their local knowledge gets lost in a foreign education system where the students are required to acquire a new set of skills. This paper presents a survey among international technology students that highlights the differences. Moreover, the paper explores the situation from the developing country perspective, and brings forth a proposal for strengthening the education capacities in the developing countries particularly in the fields of ICTs and mobile technologies. Strengthening local knowledge building would allow innovations based on local needs and potentials.
\end{abstract}

Keywords: capacity building, ICTs, developing countries, education, mobile technologies, innovations.

\section{Introduction}

International education has grown to a large and ever changing market of services. A growing number of students seek a place to study outside their home country in order to find best education in information technology and engineering [1], [2]. On the other hand, many countries and universities have an explicit internationalization policy, actively inviting overseas students to their degree programs. Internationalization is considered as a positive trend in industrialized countries, as well as a novel source of revenues. However, it also brings challenges to institutions that may not have a long experience in educating foreigners.

The worlds' most prominent universities are in an advantageous position in the global competition. Their good reputation, top position in global rankings, and recently, their ability to offer high profile MOOC's (massive open online courses) attracts top students. In a situation where they can choose the best talent and most suitable students, they do not need to adjust to a heterogeneous student body. The background of students has been screened to fit the institutions' practices. Even when these universities set up subsidiaries in other countries such as China or India, their educational offering largely remains the same. 
However, other universities face a more challenging situation: they need to work to obtain good quality applicants, they need to be able to screen among the great variety of them, and they have more pressure to adjust to student needs. Simultaneously, they need to produce competent professionals efficiently, in order to be profitable. These challenges have evoked much research and discussion among universities nationally and worldwide, generating a substantial literature on these issues. The main research approach has centered on a few questions: how to recruit efficiently, how to generate income, how to help students adapt to the new environment, and how to provide supporting studies. Only few universities have attempted to modify their core curricula to accommodate a diverse student population [2].

This paper aims at scrutinizing the need for more fundamental changes in internationalization of higher education, and technology education in particular. First, the extraordinary character of Western academic culture is discussed, focusing on the specific cognitive requirements of technology studies. Moreover, the dominance of Western science tradition is briefly compared with alternative approaches. Second, the state of education in developing countries is outlined by examples from Africa and South Asia. In the research section, the consequences of the educational disparity in international engineering education are presented through results of a survey. Finally, solutions to improve the current unsatisfactory situation are discussed. A shift of emphasis in development efforts is proposed: a move of focus from Western institutions to the research centers, universities and students in developing countries. The proposal addresses the need to enhance global innovation potential in less advantageous areas.

\subsection{Eurocentrism in Science}

Notwithstanding the knowledge that human cultures vary greatly, the academic world has functioned on the assumption of universality of Western science. The journal Behavioral and Brain Sciences published in 2010 a paper titled "The weirdest people in the world?" that invited much discussion from scientists in various fields. By "weird" people Henrich and his co-authors [3] referred to Western, Educated, Industrialized, Rich and Democratic people who had been subjects in behavioral research in the last century. The paper discussed the ethnocentric way human nature has been studied, and the implications of using a narrow sample of subjects in the study of human psychological functioning and cognition. Most of the research that has been published in psychology journals has been conducted by Western researchers (96\%), using university students as test subjects (in $67 \%$ of the cases in American samples). Henrich et al [3] argued that this kind of sample is severely biased, and in some cases could be considered as outlier of the global population. They gave examples of comparative studies that indicated very different behavioral patterns in other populations, particularly in Asian and small societies.

In particular, the Western sample of study subjects has been shown to deviate from other cultural samples in certain cognitive skills such as spatial reasoning and thinking styles, especially analytical thinking. Moreover, there are pronounced differences in performance of language related tasks. English and other Indo-European languages 
differ from most other languages in their grammatical structures, which influences the way thoughts are manipulated in the brain [4]. Similarly, brain studies [5] have been conducted mainly in rich Western countries because of the high cost of the equipment and the high skill level needed. Otherwise only in Japan, Korea and China the technology has been advanced enough to conduct brain scans on the local population [6]. Nevertheless, the inclusion of Eastern populations has revealed interesting results such as the brain differences in reading: the use of Chinese characters employs brain areas differently from using alphabetic characters [7].

The problems of Eurocentrism in research have earlier been raised in humanities and social sciences most notably by Said [8] and Bernal [9], and Asante has advocated Afrocentrism for research that concerns Africa [10]. On the other hand, ICT has its roots in Angloamerican world, and the dominance of English language and culture in internet has been discussed by Diaz Andrade and Urquhart [11].

\subsection{Universities and Research}

Asides from the traditional internationalization option where students travel to the host university, other alternatives have emerged. There are partnerships or subsidiaries of Western institutions in growing economies such as Arab countries, India, China, Brazil, and Russia [12]. The aim of these units is to educate global professionals; obviously people who are working in Western style. The subsidiaries of Western universities educate local students and, in addition, they look for business partnerships and provide opportunities for their home staff to work in other countries. Western universities also enlarge their student pool by distance education and on-line courses, with the same offerings everywhere. The Journal of Studies in International Education published a special issue on Internationalization of the Curriculum and the Disciplines in May 2013 (17:2) [2], which indicated that the matter is very new as regards to the needs to adjust the content of the curriculum.

The top ranking universities in the world are still mainly located in the US and UK, or other European or English-speaking countries. Western science tradition dominates the research to the extent that other science traditions are considered ethnic or cultural curiosities. There have been very few attempts to challenge this attitude. Medicine is a major exception, as Chinese and Eastern medical sciences are studied in local universities. There have also been attempts to create a Chinese cultural value system [13], native psychological models in Taiwan, and an African personality model [14].

Accordingly, leading journals accept only studies that follow strictly Western standards and traditions. Other research traditions have little room for development or expansion outside national circles. Davidson [15] argues for more open editorial policies and for courage to publish intellectually challenging studies from various cultural contexts, such as China and India, in the field of information systems research. The unique features of local organizations are not truly appreciated or studied when Western standards are followed strictly, and potentially new interesting theoretical viewpoints are missed. 


\section{Educational Policies in Developing Countries}

The global goal of United Nations to expand education to cover all children has been reached in theory, but the practice falls short of the goal in developing countries [16] . The Africa learning barometer shows that only $76 \%$ of children in Sub-Saharan Africa attend primary school, and the secondary school enrolment is as low as $28 \%$. Moreover, more than half of students in Grades 4 and 5 in countries such as Ethiopia, Nigeria and Zambia are below the minimum learning thresholds. Even more alarming is the finding that many teachers have difficulties in scoring acceptably in the same tests. As teacher salaries tend to be very low in African countries, competent teachers often seek better paid employment opportunities.

Nevertheless, some African countries have engaged in overly ambitious educational reforms. In Ethiopia, secondary school education is conducted in English, and in Rwanda, the school language was changed from French into English [17]. Obviously, lack of educational materials in native languages makes it attractive to choose English, and there might be additional political reasons for the choice. Many African countries have two official languages, one being the dominant local language such as Swahili, the other one the language of the former colonial master, English, French or Portuguese. Additionally, most citizens speak a local language as their mother tongue. When children enter school, they usually start studying in their second or third language.

\subsection{Kenya and Rwanda}

The Kenyan government has a Vision 2030 Economic Stimulus Programme, which has equipped 1050 secondary schools with computers: 11 PCs, 1 laptop, 1 video projector and one printer for each school. The aim of the initiative is that teachers would be able to integrate ICT into curriculum. However, there can be as many as 80 to 120 students in one class, which makes it impossible to let all students to work with computers. Moreover, school administrators are sometimes preventing teachers to access the computers, so that they are not able to prepare for the classes [18]. The main teaching method in the crowded classrooms is lecturing and repeating teacher's words. Because of the shortage of materials such as textbooks or notebooks, students have to learn the material by heart. Furthermore, they are not able to practice writing sufficiently.

In June 2013, teachers were striking for more than 3 weeks for a pay raise, but the government insisted that they could not afford paying higher salaries, which had been promised already in 1997 [19]. Obviously the policy on ICT education is not realistic under current economic pressures.

The Rwandan government decided to switch the country's entire education system from French to English in one of the most dramatic steps to date in its move away from Francophone influence [17]. Primary education in first three years is conducted in local Kinyarwanda, and after that in English. Just 8 percent of Rwandans speak French, and 4 percent speak English, according to the government, but teachers have previously been educated in French. In 2009, out of Rwanda's 31000 primary school 
teachers, only 4700 were trained in English, and out of Rwanda's 12000 secondary school teachers, only 600 were trained in English. To alleviate the situation, about 300 Ugandan teachers were employed to teach in English. It is not hard to imagine what confusion this policy has caused.

The curricula in African schools are based on western models, as well as most books and materials. The content of textbooks might be very remote from the everyday experience of students, adding an extra level of abstraction to the content to be learned. Therefore, students need to operate from two worldviews and often have two or more cultures to contend with. The education has very weak connections to the practical life of students, resulting in rote learning without reaching a decontextualization of knowledge.

\subsection{India and Bangladesh}

The multiplicity of languages in the Indian subcontinent poses an enormous challenge for the early education system, as well. In addition to nationwide languages English and Hindu, there are dominant local languages and hundreds of minor language spoken in the country. 47 languages are used as media of instruction in schools. There have been some regional projects to teach children from indigenous tribes in their first language and stepwise shift to the dominant language of the area. However, the target populations in these projects have been marginal, in Bangladesh less than 70000 [20]. Likewise, in July 2007, a project was started in the Indian state Orissa. Under that project, in 200 schools, indigenous (tribal) children from 10 language groups were being taught through their mother tongues in the first grades, with materials collected from children, parents and teachers. Later 16 more languages were added in 2008.

\subsection{Language Question in Primary and Secondary Education}

The studies in bilingualism and multilingualism have revealed a number of positive cognitive outcomes, including increased attentional control, working memory, metalinguistic awareness, and abstract and symbolic representation skills [21]. Bilingualism can greatly benefit intellectual development of the child, which extend to late adulthood [22]. Nevertheless, the benefits are lost if the child is not able to acquire fluency in her school language. For the development of abstract and scientific thought, mastery of the language is required [23]. Even mathematical skills are influenced by the language of instruction, as was shown by Saalbach and his collaborators [24]. According to their study, when language of instruction and language of application differed, the performance in arithmetic tests deteriorated. There was a significant cognitive cost involved even in this case where the subjects of the study came from a privileged Swiss German and French school system.

The above presented country cases illustrate the situation in poor developing countries. Good quality education is scare; moreover, the development policies are not well-informed or sufficiently resourced. Students who come from these countries to Western universities have already overcome many hardships: a student who is only gifted in mathematics, technology and science, has a very meagre chance to proceed 
through the system. The current situation excludes these students early in their studies. Naturally, there are also students who are fortunate to attend the best schools and who are multitalented, and finally capable to enter any university of their choice.

\section{$3 \quad$ Research and Results}

\subsection{Research Methods}

The Helsinki Metropolia University of Applied Sciences has educated international students in English in bachelor degree programs since 1994. The experience has revealed many kinds of challenges that students with developing country background confront when entering the Western engineering education system. Recently, one beginning study group consisting of 56 students answered an online questionnaire of their study experiences and previous practices. The survey included questions on the experience of computer use, earlier use of computers in studies, familiar study methods, and cognitive preferences.

The survey was given as an optional task in a study module, however, all students decided to participate. Moreover, they answered nearly all questions though none was indicated as compulsory. The ages of participants were between 18 and 34, average 23 years. 9 of the respondents were women. They came from many regions of the world: 8 from Africa (Af), 9 from Eastern Europe (EE), 9 from Western Europe (WE), 15 from South Asia (mainly Nepal, SA), 10 from East Asia (Vietnam, etc., EA), and 5 from Middle Eastern (ME) countries. They reported speaking altogether 26 different languages.

The survey consisted of multiple choice questions on technology use and understanding, questions on study modes and use of technology in the studies, questions on career aspirations and cognitive practices, and some open questions on the current studies. Respondents were given a link to the online form, which could be filled in any time. There was an identity check in order to eliminate duplicate submissions.

\subsection{Results}

The background diversity was reflected strongly in the usage of computers before studies. About one third of the respondents had been familiar with computers already when younger than 10, 24\% started using computers at age 11-15, $28 \%$ at age 15-20, and $16 \%$ were older than 20 when they started using computers regularly. The distribution of responses by nationality is shown in Fig 1. As could be expected, Africans had shorter exposure to computers than the other nationalities, whereas Western students had been using computers already in primary school age or before. The students were also asked if they ever participated in assembling a computer. To this question, Eastern Europeans gave most positive answers (67\%), and Africans least $(25 \%)$. 


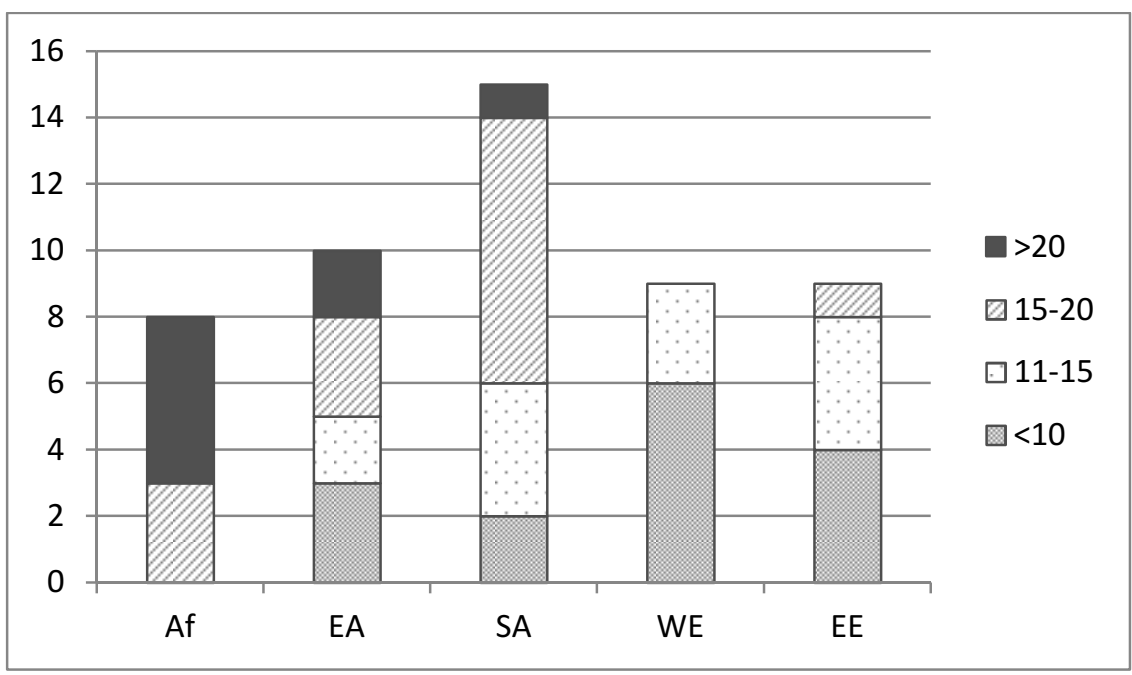

Fig. 1. Starting age of regular computer use by nationality

According to this survey, East European students had the most traditional study experience and less exposure to varied study methods such as team work, research report writing or giving presentations. The results are presented in Fig 2. In fact, Africans and West Europeans had nearly similar profiles in these modes of study. However, the implementations of methods could vary. East European students had an average 2,5 with team work familiarity and giving presentations, where 1 was "not at all familiar with" and 5 "very familiar with". On the other hand, there were no significant differences between exposure to laboratory work in physics or chemistry between groups, whereas there were striking differences between individual students: nearly half of them had no experience on chemistry laboratories, and about a third only little experience in physics labs.

Student interviews and self-reports relate of the cultural shock that they encounter when they move from developing country education to the western university system. A theoretical approach and difficulties to adapt theory into practice have been revealed in laboratory assignments that require hands-on work with the equipment, accurate measurements, or program coding. According to a study by Agiobu-Kemmer in 1984, Nigerian Yoruba children spent more time with human beings than with physical objects. The reverse was true with Scottish children who spent more time with physical objects than with human beings. This comparative study indicated that cultural factors have a strong impact on how the early upbringing introduces the physical world [14].

Moreover, earlier study results have indicated that tasks, which demanded logical reasoning, were particularly difficult to many international students. Separate tests to confirm this finding were given to students, and indeed they performed less well in different types of reasoning tasks [25]. As Henrich et al [3] in their paper showed, this finding is in accordance with general cultural cognitive differences. Analytical thinking and formal reasoning are typically skills that are produced by the western educational system and science studies [26]. 


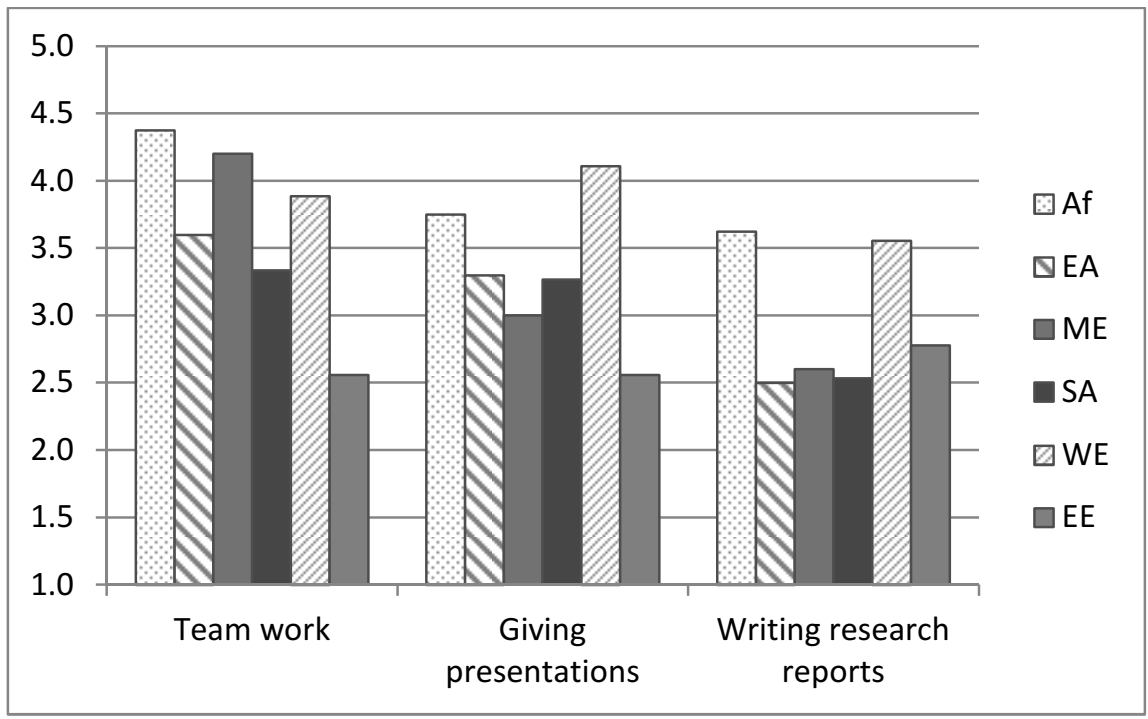

Fig. 2. Familiarity with study modes by nationality (scale 1 to 5)

\section{$4 \quad$ Globalization Solutions through Capacity Building}

\subsection{Goal to Enhance Global Innovation Potential}

The spread of mobile phone use in developing countries has been phenomenal. There are many areas in Africa where telephone cables were never installed and the mobile phone has been the first two-way communications devise that people have been able to use. This has created applications for mobile phones that are specific to developing areas such as phone banking applications, bush nurse services, and local market information distribution. There is a huge innovation potential in mobile applications due to lack of solid infrastructure. These innovations cannot be made in Western research centers where the local conditions and problems are unheard of. Moreover, the ways people prefer to operate their gadgets depend on culture, environment, education level, and context. For example, in rural areas in India, voice based interface is preferable because of illiteracy [27]. Therefore, strengthening research capability in African, Latin American and Asian universities would diversify innovations in global scale.

It is of course possible that students from developing countries create solutions for their home market when they work in western universities. Indeed, there are some examples of such innovations. A Muslim student founded a social networking web site for the Islamic community called Muxlim when he was working in Finland. The site gained popularity and international fame but finally failed to generate sufficient earnings and had to close four years later in 2008 [28]. Had the operation base been somewhere closer to large Islamic populations, the story might have ended differently. 


\subsection{Bringing in Local Capacities}

UNESCO issued an extensive report "Engineering: Issues, Challenges and Opportunities for Development" in 2010 where needs for change in engineering practice and education were discussed, and issues that are similar to this paper's arguments were raised [29]. The report called for technical capacity-building in developing countries, stressing needs for local energy solutions, participatory urban planning and infrastructure projects for sustainable development. One example came from South Sudan where sustainable construction for using appropriate technology has been developed. For engineering education, a demand for holistic and integrated systems approaches was presented, and a call was issued to share pedagogical approaches and develop curricula in this context. Sharing is particularly important for universities in developing countries who face serious constraints regarding human, financial and institutional resources to develop such curricula, learning and teaching methods. Moreover, Gaillard argued [29] that developing countries cannot rely on their substantial diaspora of experts but efforts should focus on strengthening national engineering and scientific capacity particularly through training, recruiting and retaining the next generation of scientists.

Furthermore, according to Davidson [15], information systems research would gain both depth and breadth, if researchers were willing to set their work firmly in the local cultural context. Arguably, the same requirement could be extended to all information technology research as well as industrial engineering and organizations research and education. Engineering and management practices have to adjust to local conditions and environment, and therefore, local knowledge is invaluable. Additionally, the research needs to be informed not only on local technologies but by anthropology and sociology.

Scientific traditions that developed outside Western academia have a potential to enhance global understanding if they were incorporated in local research practices. Medicine has strong local practices also on university level in East Asia, but it is only part of the vast Chinese science that has developed its own course during millennia [30]. Other less well known or advanced traditions have influenced western science but could still benefit scientific work in other areas, as well. To name some:

- Knowledge of potatoes in Peruvian countryside far exceeds the Western cultivation traditions. Peruvian farmers may have over 80 varieties on their field, each with different resistance against humidity, draught, cold, or diseases [31].

- The extensive native knowledge on medicinal herbs and nature's poisons has already been harnessed by multinational pharmaceutical companies, but how much has is benefitted local knowledge and science?

- Sustainable agriculture turns more and more to local traditions. In Madagascar local peasants can assess the productivity of a plot of land simply by looking at it, based on their experience [32]. The role that indigenous knowledge can play in truly participatory approaches to sustainable development should be acknowledged. 
- $\quad$ There are numerous ancient building traditions that have partially been abandoned. Recently, it was realized that the concrete built by Romans two millennia ago was much stronger and more long-lasting than modern concrete. The composition of that concrete is again being applied in modern construction [33].

- There has been important hydraulic engineering in many tropical areas such as Sri Lanka and Mesoamerica [34]. Advanced irrigation systems allowed the feeding of a large population base in areas that are currently tropical rainforests.

\subsection{Proposed Measures for Universities}

Universities in developing countries struggle with resource constraints. Local teaching capacities are in need of strengthening, particularly in Africa [29]. Programs to incorporate local knowledge and working styles into the curriculum and ways of doing research would offer an opportunity to lift the profile of universities, and at the same time, offer viable alternatives to the student diaspora. Recently, capacity building has become a popular approach in development projects, and it is definitely needed in engineering education, as well. Developing countries cannot act in such a demanding effort alone, as it will be long lasting and requires substantial resources. Strong partnerships and long-term commitments with Western institutions are indispensable.

Outline of the program would include measures such as:

1. Curriculum review to suit local needs: school background analyzed and taken as starting point for education. Job market needs to be understood and met.

2. Teacher training requires a collaborative effort with international professionals, local staff and consulting anthropologists or sociologist.

3. Development of teaching methods that best suit the students and increase their professional abilities. Emphasis needs to be on areas that are not supported by the primary and secondary education.

4. Creation of research programs to study native engineering science and related knowledge.

5. Creation of local innovation centers close to universities in developing countries.

\section{Conclusion}

This overview has highlighted the need to enhance current trends in international education towards stronger emphasis in developing areas. University partnerships that are largely based on western model, can become balanced, bidirectional exchanges, if universities in developing countries are given support in their capacity-building efforts. Innovations and research are diversified through fresh inputs and utilization of local traditional knowledge. The growing market potential in developing countries can be better exploited from inside than from importing ideas from industrialized 
world. The novel solutions would probably suit local conditions better, moreover, they could undoubtedly be applied in many other areas as well, and thus enrich global knowledge.

\section{References}

1. EJEE, "Special Issue: Globalization and its impact on engineering education and research. European Journal of Engineering Education 31(3) (June 2006)

2. Leask, B.: Special issue on Internationalization of the Curriculum and the Disciplines. Journal of Studies in International Education (May 2013)

3. Henrich, J., Heine, S.J., Norenzayan, A.: The weirdest people in the world? Behavioral and Brain Sciences 33(2-3), 61-83 (2010)

4. Majid, A., Levinson, S.C.: WEIRD languages have misled us, too. Behavioral and Brain Sciences 33(2-3), 103-103 (2010)

5. Chiao, J.Y., Cheon, B.K.: The weirdest brains in the world. Behavioral and Brain Sciences 33(2-3), 88-90 (2010)

6. Hansen, P., Kringelbach, M.: The Neural Bases of Reading. Oxford University Press, Oxford (2010)

7. Chen, C., Xue, G., Mei, L., Chen, C., Dong, Q.: Cultural neurolinguistics. Prog. Brain Res., 178-159 (2009)

8. Said, E.W.: Orientalism. Vintage Books, New York (1978)

9. Bernal, M.: Black Athena, vol. II. Rutgers University Press, New Brunswick (1991)

10. Milhouse, V., Asante, M., Nwosu, P. (eds.): Transcultural realities. Interdisciplinary perspectives on cross-cultural relations. Sage, Thousand Oaks (2001)

11. Diaz Andrade, A.E., Urquhart, C.: ICTs as a tool for cultural dominance: Prospects for a two-way street. Electronic Journal of Information Systems in Developing Countries 37(2), 1-12 (2009)

12. Aydarova, O.: "If Not "the Best of the West," Then "Look East": Imported Teacher Education Curricula in the Arabian Gulf. Journal of Studies in International Education 17, 284-302 (2013)

13. Fan, Y.: A classification of Chinese culture. Cross Cultural Management 7(2), 3-10 (2000)

14. Lee, Y.-T., McCauley, C.R., Draguns, J.G.: Personality and Person Perception Across Cultures. Lawrence Erlbaum Ass. Inc., Mahwah (1999)

15. Davidson, R.M.: Retrospect and prospect: information systems in the last and next 25 years: response and extension. Journal of Information Technology 25, 352-354 (2010)

16. Watkins, K.: Too Little Access, Not Enough Learning: Africa's Twin Deficit in Education (January 16, 2013),

http: / /www.brookings.edu/research/opinions / 2013/01/

16-africa-learning-watkins

17. McGreal, C.: Rwanda to switch from French to English in schools (October 14, 2008), http: / /www. guardian.co.uk/world/2008/oct/14/rwanda-france

18. Ang'ondi, E.K.: Teachers Attitudes and perceptions on the use of ICT in teaching and learning as observed by ICT champions. In: WCCE 2013, Torun, Poland. research papers, vol. 1 (2013)

19. Kenyan teachers end school strike (July 17, 2013), http://www.bbc.co.uk/news/world-africa-23346205 
20. Singh, N.K.: Globalization and Multilingualism: Case Studies of Indigenous Culture-based Education from the Indian Sub-continent and Their Implications. International Journal of Multicultural Education 15(1) (2013)

21. Adesope, O.O., Lavin, T., Thompson, T., Ungerleider, C.: A Systematic Review and MetaAnalysis of the Cognitive Correlates of Bilingualism. Review of Educational Research 80(2), 207-245 (2010)

22. Bialystok, E., Craik, F., Luk, G.: Bilingualism: consequences for mind and brain. Trends in Cognitive Sciences 16(4), 240-250 (2012)

23. Haag, N., Heppt, B., Stanat, P., Kuhl, P., Pant, H.A.: Second language learners' performance in mathematics: Disentangling the effects of academic language features. Learning and Instruction 28, 24-34 (2013)

24. Saalbach, H., Eckstein, D., Andri, N., Hobija, R., Grabner, R.H.: When language of instruction and language of application differ: Cognitive costs of bilingual mathematics learning. Learning and Instruction 26, 36-44 (2013)

25. Holvikivi, J.: Culture and cognition in information technology education. Dissertation, vol. 5. SimLab Publications, Espoo (2009)

26. Norenzayan, A.: Cultural variation in reasoning. In: Biological and Cultural Bases of Human Inference, pp. 71-95. Lawrence Erlbaum Ass., New Jersey (2006)

27. Ruohonen, M., Turunen, M., Linna, J., Hakulinen, J., Nanavatija, A., Rajput, N.: EInclusion Innovation for rural India: mobile voice and tablet based educational services. In: WCCE 2013 Proceedings, Torun. Practice Papers, vol. 2 (2013)

28. Finpro, Tekla, REACHLaw and Muxlim community receive Internationalization Awards (February 4, 2010), http: / / www . goodnewsfinland.com/archive/ news/tekla-reachlaw-and-muxlim-community-receiveinternationalization-awards /

29. UNESCO, Engineering: Issues, Challenges and Opportunities for Development, UNESCO, Paris (2010)

30. Needham, J.: Science and Civilisation in China, vol. 7. Cambridge University Press (19542004)

31. Harrison, R.: Signs, songs, and memory in the Andes. Translating Quechua language and culture. University of Texas Press, Austin (1989)

32. Bloch, M.E.: How we think they think. Anthropological approaches to cognition, memory, and literacy. Westview Press, Boulder (1998)

33. Moore, D.: The riddle of ancient roman concrete (1995), http: / /www. romanconcrete.com/docs/spillway/spillway.htm

34. Demarest, A.: Ancient Maya. The rise and fall of a rainforest civilization. Cambridge University Press, Cambridge (2002) 